Phenomenology and the Cognitive Sciences 4(4) (2005): 407-427.

\title{
Sensorimotor subjectivity and the enactive approach to experience
}

\author{
EVAN THOMPSON \\ Department of Philosophy, Universityof Toronto. (Email: evan.thompson@utoronto.ca)
}

\begin{abstract}
The enactive approach offers a distinctive view of how mental life relates to bodily activity at three levels: bodily self-regulation, sensorimotor coupling, and intersubjective interaction. This paper concentrates on the second level of sensorimotor coupling. An account is given of how the subjectively lived body and the living body of the organism are related (the body-body problem) via dynamic sensorimotor activity, and it is shown how this account helps to bridge the explanatory gap between consciousness and the brain. Arguments by O'Regan, Noë, and Myin that seek to account for the phenomenal character of perceptual consciousness in terms of 'bodiliness' and 'grabbiness' are considered. It is suggested that their account does not pay sufficient attention to two other key aspects of perceptual phenomenality: the autonomous nature of the experiencing self or agent, and the pre-reflective nature of bodily self-consciousness.
\end{abstract}

\section{The Enactive Approach}

The name "the enactive approach" and the associated concept of enaction were introduced into cognitive science by Varela, Thompson, and Rosch (1991) in order to describe and unify under one heading several related ideas. ${ }^{1}$ The first idea is that living beings are autonomous agents that actively generate and maintain their identities, and thereby enact or bring forth their own cognitive domains. The second idea is that the nervous system is an autonomous system: it actively generates and maintains its own coherent and meaningful patterns of activity, according to its operation as an organizationally closed or circular and re-entrant sensorimotor network of interacting neurons. The nervous system does not process information in the computationalist sense, but creates meaning. The third idea is that cognition is a form of embodied action. Cognitive structures and processes emerge from recurrent sensorimotor patterns of perception and action. Sensorimotor coupling between organism and environment modulates, but does not determine, the formation of endogenous, dynamic patterns of neural activity, which in turn inform sensorimotor coupling. The fourth idea is that a cognitive being's world is not a pre-specified, external realm, represented internally by its brain, but a relational domain enacted or brought forth by that being's autonomous agency and mode of coupling with the environment. This 
idea links the enactive approach to phenomenological philosophy, for both maintain that cognition bears a constitutive relation to its objects. Stated in a classical phenomenological way, the idea is that the object, in the precise sense of that which is given to and experienced by the subject, is conditioned by the mental activity of the subject. Stated in a more existential phenomenological way, the idea is that a cognitive being's world - whatever that being is able to experience, know, and practically handle - is conditioned by that being's form or structure. Such "constitution" on the part of our subjectivity or being-in-the-world is not subjectively apparent to us in everyday life, but requires systematic analysis-scientific and phenomenological - to disclose. This point brings us to the fifth idea, which is that experience is not an epiphenomenal side issue, but central to any understanding of the mind, and needs to be investigated in a careful phenomenological manner. For this reason, the enactive approach has from its inception maintained that cognitive science and phenomenology need to be pursued in a complementary and mutually informing way.

According to the enactive approach, the human mind is embodied in our entire organism and embedded in the world, and hence is not reducible to structures inside the head. Our mental lives involve three permanent and intertwined modes of bodily activity - self-regulation, sensorimotor coupling, and intersubjective interaction (Thompson and Varela 2001). Self-regulation is essential to being alive and sentient. It is evident in emotion and feeling, and in conditions such as being awake or asleep, alert or fatigued, hungry or satiated. Sensorimotor coupling with the world is expressed in perception, emotion, and action. Intersubjective interaction is the cognition and affectively charged experience of self and other. The human brain is crucial for these three modes of activity, but it is also reciprocally shaped and structured by them at multiple levels throughout the lifespan. If each individual human mind emerges from these extended modes of activity, if it is accordingly embodied and embedded in them as a "dynamic singularity"-a knot or tangle of recurrent and re-entrant processes centered on the organism (Hurley 1998) - then the "astonishing hypothesis" of neuroreductionism - that you are "nothing but a pack of neurons" (Crick 1994, p. 2) or that "you are your synapses" (LeDoux 2002) — is both a category error and biologically unsound. On the contrary, you are a living bodily subject of experience and an intersubjective mental being.

This paper focuses on the second of these modes of bodily activity, on dynamic sensorimotor activity. Recent dynamic sensorimotor approaches to perception and action have made important contributions to the scientific and philosophical understanding of consciousness (Hurley 1998; O'Regan and Noë 2001a, 2001b; Hurley and Noë 2003; Noë 2004). My aim in this paper is to build on these advances in order to address what I have elsewhere called the "body-body problem," the problem of how to relate one's subjectively lived body to the organism or living body that one is (Hanna and Thompson 2003; Thompson 2004). My approach will be to link the dynamic sensorimotor account of perceptual experience to both an enactive account of selfhood and a phenomenological account of bodily self-consciousness. 


\section{Phenomenology: Subjectivity and Bodily Self-Consciousness}

The body-body problem is a non-Cartesian way of recasting the explanatory gap between the conscious mind and the physical body. In the body-body problem, the gap is no longer between two radically different ontologies ("mental" and "physical"), but between two types within one typology of embodiment (subjectively lived body and living body). The gap is also no longer absolute, because in order to formulate it we need to make common reference to life or living being.

The body-body problem concerns the relation between one's body as one subjectively lives it and one's body as an organism in the world. This problem is in turn part of the general problem of the relation between oneself and the world, for one's living body is part of the world and one's body as one subjectively lives it is part of one's sense of self. We can thus ask two questions: how does one's lived body relate to the world and how does it relate to itself? Addressing these questions is one way to approach the body's sensorimotor subjectivity.

The relation between one's self and the world encompasses the relation between one's self and one's body. Descartes, in his Sixth Meditation, points out that one's self is not located in one's body as a pilot within a ship, but instead is "very closely joined" and "intermingled" with it, so that the two "form a unit." Nevertheless, self and body remain two, not one. MerleauPonty, in contrast, rejects this dualism. One's self is not merely embodied, but bodily: "But I am not in front of my body, I am in my body, or rather I am my body" (1962, p. 150, my emphasis). ${ }^{2}$ Yet Merleau-Ponty also refuses to understand the proposition "I am my body" in a materialist way, as meaning that I am (or my self is) nothing more than a complex physical object. Instead, he maintains the original position that I am a bodily subject, that is, a subjective object or a physical subject. In this way, he rejects the traditional concepts of mind and body, subject and object, as well as the ontologies they imply (dualism, materialism, and idealism) (see Priest 1998, pp. 56-57).

In keeping with this original view, Merleau-Ponty maintains that the relation between self and world is not primarily that of subject to object, but rather what he calls, following Heidegger, being-in-the-world. For a bodily subject it is not possible to specify what the subject is in abstraction from the world, nor is it possible to specify what the world is in abstraction from the subject: "The world is inseparable from the subject, but from a subject which is nothing but a project of the world, and the subject is inseparable from the world, but from a world which the subject itself projects" (Merleau-Ponty 1962 , p. 430). To belong to the world in this way means that our primary way of relating to things is neither purely sensory and reflexive, nor cognitive or intellectual, but rather bodily and skillful. Merleau-Ponty calls this kind of bodily intentionality "motor intentionality" (1962, p. 110, 137). His example is grasping or intentionally taking hold of an object. In grasping something we direct ourselves toward it, and thus our action is intentional. But the action does not refer to the thing by representing its objective and determinate features; it refers to it pragmatically in the light of a contextual motor goal effected by one's body (1962, p. 138). In picking up a teacup to drink from, for example, I identify it not by its objective location in space, but by its egocentric relation to my hands, and I grasp it in light of the goal of sipping from it. On the other hand, things in my surroundings, such as teacups, 
computer keys, stairways, and so on, have motor senses or meanings, what Gibson (1979) calls "affordances," which bring forth appropriate actions. Things in the world bring forth suitable intentional actions and motor projects from the subject (the subject is a project of the world), but things in the world have specific motor senses or affordances only in relation to the motor skills of the subject (the world is projected by the subject). This body-environment circuit of motor intentionality is constitutive of what Merleau-Ponty calls the "intentional arc" subtending the life of consciousness, which integrates sensibility and motility, perception and action (1962, p. 136). The intentional arc and being-in-the-world overall are neither purely first-person (subjective) nor purely third-person (objective), neither mental nor physical. They are existential structures prior to and more fundamental than these abstractions. For this reason, Merleau-Ponty maintains that they can "effect the union of the 'psychic' and the "physiological" in an existential analysis of bodily subjectivity (and its breakdown in pathology) (1962, p. 80).

In the intentional arc subtending the life of consciousness, one's body is present "not as one object among all other objects, but as the vehicle of being in the world" (Merleau-Ponty 1962, p. 139). But if one's body is the vehicle of being in the world, and is in this way a condition of possibility for experience, how or in what way can it too be experienced? This question asks about how one experiences oneself as a bodily subject, or how a lived body experiences itself as a lived body.

One way to approach bodily self-consciousness is to work back from the world, which transcends the bodily self, to the body as the correlate of its perceptual presence. A familiar theme of phenomenology, going back to Husserl, is that the lived body is a presupposition of the world's perceptual presence. Things are perceptually situated by virtue of the orientation they have to our moving and perceiving bodies. To pick up the teacup is to grasp it from a certain angle, and to hold and manipulate it in a certain manner. To listen to the radio is to hear it from a certain vantage point, which changes as one moves about the room. To see the wine bottle on the table is to view it from a certain perspective, and to see it as within or beyond one's reach. If something appears perspectivally, then the subject to whom it appears must be spatially related to it. To be spatially related to something requires that one be embodied. To say that we perceive a given profile of something, all the while aware that it has other absent but possibly present profiles, means that any profile we perceive contains references to these other profiles; each profile implicates the others. These references correspond to our ability to exchange one profile for another through our own free movement, by tilting our heads, manipulating an object in our hands, walking around something, and so on. The crucial point about the lived body in this context is twofold. First, the body functions as the "zero point," "null point of orientation," or absolute indexical "here" in relation to which things appear perspectivally. Second, the lived body cannot be reduced to yet another intentional object of perception, but always exceeds this kind of intentionality. The lived body manifests in perceptual experience not primarily as an intentional object, but as an implicit and practical "I can" of movement and motor intentionality (Husserl 1989, pp. 266-277). Husserl contrasts this "I can" with Descartes' "I think," for the intentional structure of bodily subjectivity is not I think a certain thought (ego cogito cogitatum), but rather I can and do move myself in such and such a way (Husserl 1989, pp. 159, 228, 273; see also Sheets-Johnstone 1999a, pp. 133- 
134, 230-232). In this way among others, perceptual experience involves a non-intentional and implicit awareness of one's lived body, an intransitive and pre-reflective bodily self-awareness. ${ }^{3}$

One can, of course, also experience one's body as an object, for example by looking directly at it or at one's reflection in a mirror. In such cases, one is dealing with what has been called the conscious "body image" by contrast with the unconscious "body schema" (Gallagher 1986b, 1995). The body image is the body as an intentional object of consciousness. It is consciousness of the body-as-object (Legrand 2005). In the body image, the body is experienced as owned by the experiencing subject, and the image is typically a partial representation insofar as conscious awareness usually attends to only one part or area of the body at a time. The body schema, on the other hand, is neither an intentional object of consciousness nor a partial representation of the body, but rather an integrated set of dynamic sensorimotor principles that organize perception and action in a subpersonal and nonconscious manner. This distinction between body schema and body image, however, leaves out a fundamental form of bodily experience, namely, prereflective bodily self-consciousness (Zahavi 1999, pp. 98, 240; Legrand 2005). On the one hand, the body schema is not phenomenologically available to the subject: "The body schema... is not the perception of 'my' body; it is not the image, the representation, or even the marginal consciousness of the body. Rather, it is precisely the style that organizes the body as it functions in communion with its environment" (Gallagher 1986a, p. 549). On the other hand, one's consciousness of one's body is not limited to the body image, nor is the body image the most fundamental form of bodily consciousness. On the contrary, most of the time one's body is not present as an intentional object, but is experienced non-intentionally and pre-reflectively. This kind of experience is consciousness of the body-as-subject (Legrand 2005). It corresponds to the relation of the lived body to itself, that is, to one's experience of one's body as perceiving and acting, rather than as perceived. ${ }^{4}$ Sartre calls this sort of self-consciousness "non-positional" or "non-thetic," because it does not posit one's body as an object; Merleau-Ponty calls it prereflective. Authors in the analytic philosophical tradition have described it as a nonobservational form of self-awareness (Shoemaker 1968, 1984).

Pre-reflective bodily self-consciousness is evident in touch, for we not only feel the things we touch, we feel ourselves touching them and touched by them. When I pick up a cup of hot tea, I feel the hot, smooth surface of the porcelain and the heat penetrating my fingers, and these sensations linger for a time after I have put the cup back down on the table. Such bodily experience offers not only the experience of physical events that relate one's body to things, but also the experience of sensorial events that relate one's subjectively lived body to itself. Usually these sensorial events are ones in which one's body does not sense itself explicitly. In picking up the teacup, I live through the heat in my fingers, but the perceptual object is the teacup, not myself. But one's body can also sense itself, as when one hand touches the other. In this case, the one touching is the thing touched, and the thing touched senses itself as the one being touched.

Phenomenologists have reflected on this sort of bodily self-experience for a number of important reasons. There is a dynamic linkage of outward perception and inward feeling, so that one encounters one's own bodily sentience directly. One's body shows itself to be a material thing, but one 
animated from within by sensation and motility (Husserl 1989, p. 153). This form of bodily self-consciousness makes vividly apparent the lived body's unique status as a physical subject:

When my right hand touches my left, I am aware of it as a "physical thing." But at the same moment, if I wish, an extraordinary event takes place: here is my left hand as well starting to perceive my right, es wird Leib, es empfindet [it becomes body, it senses]. ${ }^{5}$ The physical thing becomes animate. Or, more precisely, it remains what it was (the event does not enrich it), but an exploratory power comes to rest upon or dwell in it. Thus I touch myself touching: my body accomplishes "a sort of reflection." In it, through it, there is not just the unidirectional relationship of the one who perceives to what he perceives. The relationship is reversed, the touched hand becomes the touching hand, and I am obliged to say that the sense of touch here is diffused into the body - that the body is a "perceiving thing," a "subjectobject" (Merleau-Ponty 1964, p. 166).

Yet the touching and being-touched experiences never absolutely coincide. The two hands are never simultaneously touched and touching in relation to each other, but instead alternate their roles spontaneously (Merleau-Ponty 1962, p. 93). This spontaneous alternation is an expression of the body's dynamic sensorimotor relation to its own subjectivity, and this kind of selfrelation distinguishes one's body from other objective things one encounters in perception (see Merleau-Ponty, 1962, p. 93; Husserl 1960, p. 97).

In this experience we can also catch a glimpse of how sensorimotor subjectivity can implicate a kind of sensorimotor intersubjectivity. A dynamic process of "self-othering" takes place in this experience, so that one's body becomes other to itself. When my left hand touches my right (or when I experience my body in other ways), there arises the possibility of experiencing myself in a way that anticipates both the way in which another bodily subject would experience me and the way in which I would experience the other. Bodily self-awareness is in this way conditioned by a form of otherness or alterity. According to Husserl, this self-othering dynamic is a precondition for empathy, in the broad sense of being able to recognize others as subjects like oneself on the basis of their bodily presence (Zahavi 2003, p. 113). It is precisely the body's double status of being a "subject-object," a subjectively lived body (Leib/körperlicher Leib) and an objective living body (Körper/leiblicher Körper), as well as the dynamic interplay between ipseity (I-ness) and alterity (otherness) inherent in this ambiguity, that grounds one's ability to recognize other bodies as bodily subjects like oneself (see Thompson 2001, 2005). These brief phenomenological reflections are enough to show that consciousness involves the body in a unique double way. One experiences one's body as both subject and object. One's body is the intentional object of one's consciousness when one attends to one or another aspect or part of it. The content of this kind of bodily awareness corresponds to the body image or one's body-as-object. But bodily consciousness cannot be reduced to this sort of experience, because one also pre-reflectively and nonintentionally experiences one's body-as-subject. The challenge for any scientific account of consciousness is to preserve this unique double character of bodily self-consciousness.

Hence any scientific account must meet these two criteria: it must account for the ways in which one's body is intentionally directed toward the world, 
and it must account for a form of non-intentional self-awareness that does not imply perceptual identification of one's body as an object.

Legrand has worked to give an account of bodily self-consciousness that meets these criteria (Legrand 2005). She argues that bodily consciousness in the case of action consciousness is reducible neither to awareness of one's intentions to act nor to proprioception understood as an internal mode of identification of the body, and therefore cannot be based on either efferent or afferent mechanisms alone. Bodily consciousness consists in experiencing one's body as a locus of the convergence of perception and action, and therefore depends on a matching of sensory and motor information, so that perception and action are coherent (see also Hurley 1998, pp. 140-143). There must be a specific match between (i) the intention to act, (ii) the motor consequences of this intention, including the guidance of bodily movements during the executed action, and (iii) the sensory consequences of this action, including both proprioception and exteroception.

An important implication of this account is that neural correlates of selfconsciousness will remain explanatorily opaque with respect to mental life as long as we understand them only in terms of their intrinsic neural properties and not in the dynamic sensorimotor context of the body as a whole (Thompson and Varela 2001; Hurley and Noë 2003; Legrand 2003). This point brings us to dynamic sensorimotor accounts of perceptual experience and their significance for the body-body problem.

\section{Enriching the Dynamic Sensorimotor Approach to Consciousness}

In a recent article on the "explanatory gap" between consciousness and the brain, Nicholas Humphrey remarks, "there can be no hope of scientific progress so long as we continue to write down the identity [mental state $m=$ brain state $b]$ in such a way that the mind terms and the brain terms are patently incommensurable... We shall need to work on both sides to define the relevant mental states and brain states in terms of concepts that really do have dual currency - being equally applicable to the mental and the material" (Humphrey 2000, pp. 7, 10).

This strategy of working on both sides of the gap is precisely the one pursued by the dynamic sensorimotor approach. Rather than looking to the intrinsic properties of neural activity in order to explain experience, this approach looks to the dynamic sensorimotor relations among neural activity, the body, and the world. The concept that has dual currency for this approach is the concept of dynamic sensorimotor activity. On the mental side, perceptual experiences are explicated as ways of acting, constituted in part by the perceiver's implicit and practical knowledge or skillful mastery of the relation between sensory experience and movement (O'Regan and Noë 2001a; Noë 2004). The senses have different characteristic patterns of sensorimotor dependence, and perceivers have an implicit, skillful mastery of these differences. On the brain side, neural states are described not at the level of their intrinsic neurophysiological properties or as neural correlates of mental states, but rather in terms of how they participate in dynamic sensorimotor patterns involving the whole active organism (Hurley and Noë 2003). 
The dynamic sensorimotor approach is best understood not as an attempt to close the explanatory gap in a reductionist sense, but instead as an attempt to bridge the gap by deploying new theoretical resources for understanding perceptual experience and neural processes in a coherent and overarching dynamic sensorimotor framework. For each modality of perceptual experience - seeing, hearing, touching, and so on-there is a corresponding pattern of sensorimotor interdependence that is constitutive of that modality. What it is to experience the world perceptually is to exercise one's bodily mastery or know-how of certain patterns of sensorimotor dependence between one's sensing and moving body and the environment. If distinct sensorimotor patterns are in this way constitutive of seeing, hearing, and so forth, then it does not make sense to ask, "Why do these sensorimotor patterns go with what it is like to see, rather than to hear or to touch?" By contrast, one can always raise this sort of question with regard to neural activity in a particular brain area: "Why should brain activity in this region of cortex go with what it is like to see, rather than to hear or to touch?" The way to satisfy the hunger behind this sort of question is to give an account that embeds local neural activity in its dynamic sensorimotor context. For these reasons, sensorimotor patterns are more promising than mere neural correlates of consciousness (Hurley and Noë 2003, pp. 146-147; Noë and Thompson 2004a, 2004b).

The foregoing question about the relation between cortical activity and perceptual experience concerns the explanatory gap in what Hurley and Noë (2003) call its comparative (intermodal) form. ${ }^{6}$ But there is also what they call the absolute gap: "Why should neural processes be 'accompanied' by any conscious experience at all?" (Hurley and Noë 2003, p. 132). The absolute gap is the familiar hard problem of consciousness (Nagel 1974; Chalmers 1996). Hurley and Noë (2003) address the comparative gap, not the absolute gap. They admit that to use a dynamic sensorimotor account to bridge the comparative gap is not to bridge the absolute gap of why there is experience at all. Their aim is to explain why the agent has experience like this rather than like that, but not to explain why there is something it is like to be the agent at all. On the contrary, their account presupposes consciousness and subjectivity, because it starts from the assumption that there is something it is like to be the agent in the first place.

O'Regan, Noë, and Myin, however, argue that the sensorimotor approach is also able to bridge the absolute gap (O'Regan and Noë 2001a, 2001b; Myin and O'Regan 2002; O'Regan, Myin and Noë, this volume). Their proposal is relevant to the body-body problem. Examining their account will serve to indicate why and how the dynamic sensorimotor approach should be combined with both an enactive account of autonomous selfhood and a phenomenological account of bodily self-consciousness.

The strategy of these authors is to give a sensorimotor account of certain characteristic properties of sensory experience. These properties are "forcible presence," "ongoingness," "ineffability," and "subjectivity," and they are supposed to constitute the phenomenal character of conscious experience:

Ongoingness means that an experience is experienced as occurring to me, or happening to me here, now, as though I was inhabited by some ongoing process like the humming of a motor. Forcible presence is the fact that, contrary to other mental states like my knowledge of history, for example, a sensory experience imposes itself upon me from the outside, and is present to me without my making any mental effort, 
and indeed is mostly out of my voluntary control. Ineffability indicates that there is always more to the experience than what we can describe in words. Finally, subjectivity indicates that the experience is, in an unalienable way, my experience. It is yours or mine, his or hers, and cannot be had without someone having it. But subjectivity also indicates that the experience is something for me, something that offers me an opportunity to act or think with respect to whatever is experienced (Myin and O'Regan 2002, p. 30).

Forcible presence and ongoingness are to be explained in terms of "bodiliness" (or corporality) and "grabbiness" (or alerting capacity) two complementary features of the way sensorimotor systems operate, and that distinguish perceptual awareness from non-perceptual awareness or thought. Bodiliness is the dependence of sensory stimulation on one's bodily movements. The greater the change is to sensory stimulation resulting from bodily movement, the higher the degree of bodiliness. Thus one's visual experience of a book in front of one has a high degree of bodiliness, compared with one's non-perceptual awareness of a book in the next room. Blinking, eye movements, and head and torso movements modulate the way the book affects one's sensory apparatus, but make no difference to the book in the next room. Grabbiness is the tendency of something to attract one's attention. Vision has high grabbiness, for sudden changes in the visual scene around one immediately attract one's attention. Thus movements or changes to the book in front of one will immediately affect one's sensory apparatus in an attentiongrabbing way, whereas movements of the book in the next room will not. Bodiliness and grabbiness are supposed to explain forcible presence and ongoingness in the following way:

(1) the book forces itself on us because any movement of the book causes us to direct our attention (our processing resources) to it. (2) The slightest movement of the relevant parts of our bodies modifies the sensory stimulation in relation to the book. Metaphorically, it is as if we are in contact with the book... [W] can explain ongoingness in a similar way... The sense of an ongoing qualitative state consists, (a) in our understanding that movements of the body can currently give rise to the relevant pattern of sensory stimulation (bodiliness), and (b) in our understanding that the slightest change in what we are looking at will grab our attention and in that way force itself on us. In this way we explain why it seems to us as if there is something ongoing in us without actually supposing that there is anything ongoing, and in particular, without supposing that there is a corresponding ongoing physical mechanism or process (O’Regan and Noë 2001b, p. 1012).

There remain the two characteristics of ineffability and subjectivity. According to the sensorimotor approach, perceptual experiences are active manifestations of a kind of skillful knowledge and are defined in terms of potential for action. In general it is difficult to describe the knowledge underlying a skill. Thus ineffability is explained by our being unable to describe verbally our implicit, practical knowledge of the sensorimotor patterns constitutive of perceptual experience. Subjectivity is explained in the following way:

Someone is perceptually aware of something because she is interacting with it. It is her putting all the resources she has onto whatever she is conscious of that makes her conscious of it. So, once she is conscious of it, it is 'for her'-it is her 
subjective project to which she is devoting all her capacities. So, consciousness is, by definition, 'for the subject' (Myin and O'Regan 2002, p. 39).

This account is illuminating to the extent that it accounts for important characteristics of experience in dynamic sensorimotor terms. But I believe it is incomplete in two ways. First, it needs to be underwritten by an enactive account of selfhood or agency in terms of autonomous systems. Second, it needs to enrich its account of subjectivity to include pre-reflective bodily selfconsciousness.

The dynamic sensorimotor approach needs a notion of selfhood or agency, because to explain perceptual experience it appeals to sensorimotor knowledge. Knowledge implies a knower or agent or self that embodies this knowledge. But what organization does a sensorimotor system need to have in order to be a genuine sensorimotor agent with a correlative sensorimotor environment or Umwelt in von Uexküll's (1957) sense?

According to the enactive approach, agency and selfhood require that the system be autonomous. An autonomous system is a self-defining or selfdetermining system, by contrast with a system defined and controlled from the outside or a heteronomous system. An autonomous system is one whose component processes meet two conditions: (i) they recursively depend on each other for their generation and their realization as a system, and (ii) they constitute the system as a unity in whatever domain they exist (Varela 1979, p. 55). An autonomous system can also be defined as a system that has organizational and operational closure: the result of any process within the system is another process within the system (Varela 1979, pp. 55-60; Varela and Bourgine 1991). ${ }^{7}$ The paradigm is a living cell. Its components are molecular and exist in the chemical domain, but the system as a whole is a biological individual or agent. Its individuality and agency are based on its having a self-producing or autopoietic organization: it is organized as a selfproducing and self-maintaining network that constructs its own membrane boundary and actively regulates its background or boundary conditions so as to remain viable in its environment (Maturana and Varela 1980; Bitbol and Luisi 2004; Bourgine and Stewart 2004; Di Paolo, this volume). It is thanks to this autopoietic organization that the system qualifies as a genuine autonomous agent.

This core form of biological autonomy is recapitulated in a more complex form in metazoan organisms with nervous systems. The fundamental logic of the nervous system is to couple movement and a stream of sensory information in a continuous circular fashion (Maturana and Varela 1987). The nervous system links sensory surfaces (sense organs and nerve endings) and effectors (muscles, glands) within the body, and thereby integrates the organism, holding it together as a mobile unity, as an autonomous sensorimotor agent. The nervous system establishes and maintains a sensorimotor cycle, whereby what the animal senses depends directly on how its moves, and how it moves depends directly on what it senses. This operationally closed organization of the nervous system underwrites the animal's autonomy, such that it meets the environment on its own sensorimotor terms.

Whereas biological selfhood in its cellular form arises as a consequence of autopoiesis, sensorimotor selfhood arises as a consequence of the way the nervous system integrates the metazoan body. In each case the organization of 
the system is produced by the system itself. This self-producing organization defines the system's identity and determines a perspective or point of view in relation to the environment. Systems organized in this way enact or bring forth what counts as information for them; they are not transducers or functions for converting input instructions into output products. For these reasons, it is legitimate to invoke the concepts of selfhood and agency to describe them.

As an example consider motile bacteria swimming uphill in a food gradient of sugar. These cells tumble about until they hit on an orientation that increases their exposure to sugar, at which point they swim forward, upgradient, toward the zone of greatest sugar concentration. This behavior happens because the bacteria are able to sense chemically the concentration of sugar in their local environment through molecular receptors in their membranes, and they are able to move forward by rotating their flagella like a propeller. These bacteria are autopoietic and embody a dynamic sensorimotor loop: the way they move (tumbling or swimming forward) depends on what they sense, and what they sense depends on how they move. This sensorimotor loop both expresses and is subordinated to the cell's autonomy, to the maintenance of its autopoiesis. As a result, every sensorimotor interaction and every discriminable feature of the environment embodies or reflects the bacterial perspective. Thus although sucrose is a real and present condition of the physicochemical environment, its status as food is not. That sucrose is a nutrient is not intrinsic to the sucrose molecule, but is a relational feature, linked to the bacterium's metabolism. Sucrose has significance or value as food, but only in the milieu that the organism itself enacts. Thus, thanks to the organism's autonomy, its niche has a "surplus of significance" compared with the physicochemical environment (Varela 1991, 1997).

Compare this case to O'Regan and Noë's example of a missile guidance system. They write that this system "'knows all about' or 'has mastery over' the possible input/output relationships that occur during airplane tracking" (O'Regan and Noë 2001a, p. 943). In this case, however, unlike the bacteria (or organisms with nervous systems), the "sensorimotor knowledge" seems merely attributed to the system by the observer, not original to the system itself. There is no genuine sensorimotor knowledge or mastery in this system, because the system is not autonomous (does not have an autonomous organization). It is not a self-producing and self-maintaining system that actively regulates its own boundary conditions so as to ensure its continued viability. It does not produce and maintain its own sensorimotor identity as an invariant of its sensorimotor interactions with the environment. It thus has no genuine sensorimotor agency or selfhood, and therefore cannot be said to embody any genuine perspective or point of view on the world.

Adding an enactive account of selfhood to the dynamic sensorimotor approach goes only part way toward addressing the body-body problem. In addition we need to include subjectivity in the sense of a phenomenal feeling of bodily selfhood linked to a correlative feeling of otherness.

This point brings us back to pre-reflective bodily self-consciousness. When I pick up a bottle and grasp it with my hands, I experience the bottle as other to me, but the feeling of grasping the bottle is immediately experienced as mine. ${ }^{8}$ The intentional object of my tactile experience is the bottle, but at the same time I live through my grasping feeling in a non-intentional (nonobject-directed) manner. To experience the feeling as mine I do not have to 
identify it as mine. Instead, the feeling comes with an intrinsic "mineness" or first-personal givenness that constitutes its subjectivity (Zahavi 2002, 2004; Kriegel 2003a, 2003b).

Myin and O'Regan (2002), as we have seen, claim to account for the subjectivity of perceptual experience. Their strategy is to "de-reify" experience by teasing apart its different phenomenal characteristicsongoingness, forcible presence, ineffability, and subjectivity. But ongoingness, forcible presence, and ineffability all involve subjectivity in a constitutive way: "Ongoingness means that an experience is experienced as occurring to me, or happening to me here, now, as though I was inhabited by some ongoing process like the humming of a motor. Forcible presence is the fact that... a sensory experience imposes itself upon me from outside, and is present to me without any mental effort, and indeed is mostly under my voluntary control" (Myin and O'Regan 2002, p. 30, my emphasis). Each italicized phrase describes an aspect of the subjectivity or first-personal character of experience. Similarly, ineffability means that my perceptual experience seems indescribable to me in certain respects. Myin and O'Regan devote most of their efforts to explaining ongoingness and forcible presence, and what they write about subjectivity does not address the first-personal character and non-object-directed or intransitive self-awareness constitutive of experience (or experiencing), but instead the conscious access the subject has to the intentional objects of perceptual experience. They propose that consciousness is "for the subject," because to be conscious of $\mathrm{X}$ is to put all one's skillful sensorimotor and attentional resources onto X, such that one is aware not simply of $\mathrm{X}$, but also of the opportunities for further action or thinking that $\mathrm{X}$ affords.

This explanation is plausible as an account of what it is for a given object $X$ to be "for the subject" (or accessible to the subject): $\mathrm{X}$ is the intentional object of the subject's attention (or is available to attention). But this account does not explain what it is for one's perceptual experience of $X$ to be intransitively self-aware and thus to have first-personal givenness. For example, this account might explain what it is for the wooly red of the carpet to be the content of my current visual experience, but it does not explain what it is for the experience of seeing the wooly red of the carpet to be phenomenally manifest as mine. In other words, we are given an account of conscious access to the intentional objects of perceptual experience, but not of subjectivity in the sense of the first-personal quality of experience as such. Thus there remains a significant gap in this account.

A related problem is that this account identifies all consciousness with transitive or object-directed experience, and all transitive consciousness with attention (O'Regan and Noë 2001a, pp. 944, 955, 960). These identifications seem too narrow. Consider first the identification of transitive consciousness with attention. Block gives the example of being engaged in an intense conversation while a power drill rattles away outside the window (Block 1997, pp. 386-387). Engrossed in the conversation, one does not notice the noise, but then eventually and all of sudden one does notice it. Block uses this example to illustrate the distinction between a mental state's being "phenomenally conscious" (subjectively experienced) and its being "access conscious" (accessible to thought, verbal report, and action guidance). His proposal is that insofar as one is aware of the noise all along, one is phenomenally conscious of it, but not access conscious of it. When one 
notices the noise, one becomes access conscious of it (and perhaps also realizes that one has been hearing it all along), so that one now has both phenomenal consciousness and access consciousness of the sound.

O'Regan and Noë (2001a, p. 964) dispute this description, claiming that one does not hear the drill until one notices and attends to it. One's auditory system may respond selectively to the noise, but one makes no use of the information provided thereby, nor is one poised to make any use of that information, until one notices the drill. Hence there is no ground for thinking we have a case of phenomenal consciousness without access consciousness. In the absence of access, there is no phenomenal consciousness.

From a phenomenological point of view, both descriptions seem somewhat flat. The experiential difference between not noticing and then noticing a noise is treated statically, as if it were a discrete state transition, with no extended temporal dynamics, and there is no differentiation within the temporal dynamics of the experience between implicit and explicit aspects. One may notice a noise in an implicit way, in which case one lives through the sound without grasping it as a distinct object. One may also notice a noise in the sense of turning one's attention to it or having one's attention be captured by it, in which case it is grasped as a distinct object. Finally, at an implicit level, it is important to differentiate between moments of comparatively weak and strong affective force on the part of the noise as the experience unfolds. ${ }^{9}$

Two distinctions from Husserl's phenomenology are relevant here (see Husserl 2001). The first is between activity and passivity. Activity means taking a cognitive position in acts of attending, judging, valuing, wishing, and so forth. Passivity means being involuntarily influenced and affected by something. The second is between receptivity and affectivity: "Receptivity is... the first, lowest, and most primitive type of intentional activity, and consists in responding to or paying attention to that which is affecting us passively. Thus, even receptivity, understood as a mere 'I notice' presupposes a prior affection" (Zahavi 1999, p. 116). "Affection" means being affectively influenced or perturbed. The idea is that whatever becomes noticeable must have already been affecting one and must have some kind of affective force or allure (affective grabbiness) in relation to one's attention. As psychologists know, attention is typically affectively motivated (Derryberry and Tucker 1994). Affective allure or grabbiness thus implies a dynamic gestalt or figureground structure: Something becomes noticeable, at whatever level, due to the strength of its allure or grabbiness, emerging into affective prominence, salience, or relief, while other things become less noticeable due to the comparative weakness of their allure. This dynamic interplay of passivity and activity, affectivity and receptivity, expresses a constant "operative intentionality" that underlies object-directed or intentional consciousness (Merleau-Ponty 1962, p. xviii).

These considerations suggest that hearing the sound before noticing it should be counted as a case of phenomenal consciousness. One does consciously hear the sound before noticing it, if "noticing" means turning one's attention to it. The sound is experienced implicitly and pre-reflectively. One lives through the state of being affected by the sound without thematizing the sound or one's affectedness by it. This prereflective consciousness counts as phenomenal consciousness, because the sound's appearance and affective influence have a subjective or first-personal character. Hence it does not seem 
right to say that one has no experience of the sound at all until one notices it. Nevertheless, there is no reason to believe that this experience is not also a case of access consciousness. After all, one is poised to make use of one's implicit and prereflective hearing of the sound. The content of the experience is at least accessible, even if it is not accessed explicitly. ${ }^{10}$ On the other hand, if we imagine that one is not cognitively poised in any way to rely on the sound, then we would need a reason to believe that one is nonetheless phenomenally conscious of it rather than simply discriminating or differentially responding to it nonconsciously, but no reason is forthcoming simply from this example.

Consider now the claim that all consciousness is transitive consciousness. We have already seen that intransitive or non-intentional bodily selfconsciousness is constitutive of perceptual experience. When I see the wooly red of the carpet, I am transitively conscious of the wooly-red carpet, but I also consciously experience my seeing (my seeing is intransitively selfaware). When I grasp the bottle, I am transitively aware of the bottle, but I also consciously experience my grasping (my grasping is intransitively selfaware). It does not seem right to maintain either that my seeing or grasping is not conscious, or that I am merely poised to become transitively conscious of them. The first interpretation looks incoherent. It is hard to make sense of the idea that one could have a conscious perception of $\mathrm{X}$ without experiencing one's perception of $\mathrm{X}^{11}$ The second interpretation, on the other hand, is conceptually and phenomenologically unclear. Does one's being poised to become transitively aware of one's perceiving (through an attentional shift) itself have a phenomenal or subjective character? If it does not, then it would seem to be an unconscious disposition or a subpersonal disposition of one's nervous system. The problem then is to explain how a completely unconscious or subpersonal disposition can account for the apparently occurrent character of non-intentional bodily self-consciousness. On the other hand, if one's being thus poised does have a phenomenal and subjective character-if one feels thus poised - then that feeling needs to be accounted for as part of the subjective character of experience. Accounting for this feeling cannot be done simply in terms of transitive consciousness, precisely because it does not have a transitive or subject-object structure. On the contrary, it would seem to be another way of describing or getting at the phenomenon of intransitive and non-intentional bodily self-consciousness.

The upshot of these reflections is that a complete account of perceptual experience requires an account of non-intentional (intransitive, non-objectdirected), pre-reflective bodily self-consciousness. Although the dynamic sensorimotor approach has made significant progress in accounting for transitive perceptual consciousness, further work needs to be done to address bodily self-consciousness. This work will be crucial for progress on the bodybody problem.

\section{Conclusion}

My aim has been to show that the dynamic sensorimotor approach to perceptual experience can be profitably combined with an enactive account of selfhood and a phenomenological account of bodily self-consciousness. I also 
hope to have shown that this synthesis is needed in order to make headway on the explanatory gap recast as the body-body problem.

Central to the enactive approach to experience is the idea that cognitive science and phenomenology can be linked in a reciprocal and mutually illuminating way. The enactive approach uses phenomenology to explicate cognitive science and cognitive science to explicate phenomenology. Concepts such as lived body and organism, bodily selfhood and autonomous agency, the intentional arc and dynamic sensorimotor dependencies, can thus become mutually illuminating rather than merely correlational concepts. This paper is meant as a step in this direction. ${ }^{12}$

\section{Notes}

1. Varela first thought of the name "the enactive approach" in the summer of 1986 in Paris when he and Thompson began writing The Embodied Mind. At one point before introducing the term "enactive," Varela had been using "the hermeneutic approach" to emphasize the affiliation of his ideas to the philosophical school of hermeneutics - an affiliation also emphasized by other theorists of embodied cognition at the time (see Varela, Thompson, and Rosch 1991, pp. 149-150). The first and second ideas summarized above were presented in Varela's 1979 book, Principles of Biological Autonomy. They were developed with Humberto Maturana, and grew out of Maturana's earlier work on the biology of cognition (Maturana 1969, 1970; Maturana and Varela 1980, 1987). The remaining ideas were presented by Varela, Thompson, and Rosch (1991), by Thompson, Palacios, and Varela (1992), and were elaborated by Varela and Thompson in a number of subsequent papers (e.g., Varela 1991, 1997; Thompson 2001; Thompson and Varela 2001; Varela and Thompson 2003).

2. I have slightly modified the English translation. The French reads: "Mais je ne suis pas devant mon corps, je suis dans mon corps, ou plutôt je suis mon corps."

3. Pre-reflective bodily self-consciousness is close to Hurley's notion of "perspectival selfconsciousness" (Hurley 1998, pp. 140-143). Perspectival selfconsciousness is awareness of one's own intentional motor agency in perception. This sort of awareness is constitutive of having a unified perspective on the world, such that one is able to keep track of the interdependence of one's perception and action. According to Hurley, perspectival self-consciousness does not involve conceptually structured thought or inference (but see Noë 2002 and 2004). Perspectival self-consciousness is not equivalent to everything phenomenologists mean by the notion of prereflective self-consciousness, but to that part of bodily self-consciousness that involves action consciousness.

4. Pre-reflective bodily self-consciousness is consciousness of one's body-assubject and therefore is not equivalent to proprioception, if proprioception is understood as a mode of perceptual awareness of one's body-as-object. Whether proprioception should be understood this way is a matter of debate among philosophers. Bermúdez (1998) argues that proprioception is a form of perception; Gallagher (2003) argues that it is a form of non-perceptual bodily awareness; Legrand (2005) argues that it is a form of perception but is not sufficient for pre-reflective bodily self-consciousness.

5. Merleau-Ponty here alludes to a passage from Husserl's Ideas II (Husserl 1989, p. 152). 
6. The comparative gap can also take an intramodal form: Why does certain neural activity go with or give rise to visual experience of red, for example, rather than green? See Hurley and Noë (2003) for further discussion.

7. Varela's "Closure Thesis" states, "Every autonomous system is organizationally closed" (Varela 1979, p. 58). He indicates that this thesis is meant to be analogous to Church's Thesis that any calculation is formally equivalent to a recursive function. "Recursive function" is a technical notion used to define the imprecise notion of a calculation. Similarly, "organizational closure" is a technical notion used to define the imprecise notion of autonomy. In either case the thesis is not subject to proof (hence is not a theorem), but can be taken as a challenge to find a counterexample (something that intuitively counts as a calculation but is not formally equivalent to a recursive function; something that intuitively counts as autonomous but does not have organizational closure).

8. I do not mean to imply that something is experienced as other simply because it is external to one's biological membrane. As Merleau-Ponty points out, the blind man's stick is incorporated into his lived body (Merleau-Ponty 1962, p. 143).

9. Compare Husserl's description of this sort of case: "a soft noise becoming louder and louder takes on a growing affectivity in this materially relevant transformation; the vivacity of it in consciousness increases. This means that it exercises a growing pull on the ego. The ego finally turns toward it. However, examining this more precisely, the modal transformation of affection has already occurred prior to the turning toward. Along with a certain strength that is at work under the given affective circumstances, the pull proceeding from the noise has so genuinely struck the ego that it has come into relief for the ego, even if only in the antechamber of the ego. The ego already detects it now in its particularity even though it does not yet pay attention to it by grasping it in an attentive manner. This 'already detecting' means that in the ego a positive tendency is awakened to turn toward the object, its 'interest' is aroused-it becomes an acutely active interest in and through the turning toward in which this positive tendency, which goes from the ego-pole toward the noise, is fulfilled in the striving-toward. Now we understand the essential modal transformation that has occurred here. First an increasing affection; but the affective pull is not yet, from the standpoint of the ego, a counter-pull, not yet a responsive tendency toward the allure issuing from the object, a tendency that for its part can assume the new mode of an attentively grasping tendency. There are further distinctions that can be made here, but they do not concern us at this time" (Husserl 2001, p. 215). This description is explicitly temporal and dynamic; it displays phenomenal consciousness as characterized by continual, graded transformations of accessibility or access potential; and it roots modal transformations of consciousness in the dynamics of affect and movement tendencies (emotion).

10. Church makes a similar point: "the accessibility (i.e., the access potential) of the hearing experience is evident from the fact that I do eventually access it. Further, it seems that I would have accessed it sooner had it been a matter of greater importance-and thus, in a still stronger sense, it was accessible all along. Finally, it is not even clear that it was not actually accessed all along insofar as it rationally guided my behaviour in causing me to speak louder, or move closer, and so forth" (Church 1997, p. 426).

11. I leave aside the issue of whether this sort of self-consciousness is best analyzed nonegologically (à la Husserl's Logical Investigations or Sartre's Transcendence of the Ego) or egologically (à la Husserl's transcendental phenomenology, as expressed for example in his Cartesian Meditations).

12. This paper is based on material from my forthcoming book, Mind in Life: Biology, Phenomenology, and the Sciences of Mind. 


\section{References}

Bermúdez, J.L. 1998. The Paradox of Self-Consciousness. Cambridge, MA: The MIT Press.

Bitbol, M. and Luisi, P.L. 2005. Autopoiesis with or without cognition: defining life at its edge. Journal of the Royal Society Interface 1: 99-107.

Block, N. 1997. On a confusion about a function of consciousness. In N. Block, O. Flanagan, and G. Güzeldere (eds.), The Nature of Consciousness: Philosophical Debates, pp. 375-416. Cambridge, MA: The MIT Press/A Bradford Book.

Bourgine, P. and Stewart, J. 2004. Autopoiesis and cognition. Artificial Life 20: $327-$ 345.

Chalmers, D. J. 1996. The Conscious Mind: In Search of a Fundamental Theory. New York: Oxford University Press.

Church, J. 1997. Fallacies or analyses? In N. Block, O. Flanagan, and G. Güzeldere eds.), The Nature of Consciousness: Philosophical Debates, pp. 425-426. Cambridge, MA: The MIT Press/A Bradford Book.

Crick, F. 1994. The Astonishing Hypothesis. The Scientific Search for the Soul. New York: Scribners.

Derryberry, D. and Tucker, D.M. 1994. Motivating the focus of attention. In P.M. Niedenthal and S. Kitayama (eds.), The Heart's Eye: Emotional Influences in Perception and Attention, pp. 167-196. New York: Academic Press.

Di Paolo, E. 2005. Autopoiesis, adaptivity, teleology, agency. Phenomenology and the Cognitive Sciences, this volume.

Gallagher, S. 1986a. Lived body and environment. Research in Phenomenology 16: 139-170.

Gallagher, S. 1986b. Body image and body schema: a conceptual clarification. The Journal of Mind and Behavior 7: 541-554.

Gallagher, S. 2003. Bodily self-awareness and object perception. Theoria et Historia Scientarium: International Journal for Interdisciplinary Studies 7: 53-68.

Gibson, J.J. 1979. The Ecological Approach to Visual Perception. Boston: Houghton Mifflin.

Hanna, R. and Thompson, E. 2003. The mind-body-body problem. Theoria et Historia Scientiarum: International Journal for Interdisciplinary Studies 7.

Humphrey, N. 2000. How to solve the mind-body problem. Journal of Consciousness Studies 4: 5-20.

Hurley, S.L. 1998. Consciousness in Action. Cambridge, MA: Harvard University Press.

Hurley, S.L. and Noë, A. 2003. Neural plasticity and consciousness. Biology and Philosophy 18: 131-168.

Husserl, E. 1960. Cartesian Meditations: An Introduction to Phenomenology. Trans. Dorian Cairns. Dordrecht: Kluwer Academic Publishers.

Husserl, E. 1989. Ideas Pertaining to a Pure Phenomenological Philosophy and to a Phenomenological Philosophy, Second Book. Trans. R. Rojcewicz and A. Schuwer. Dordrecht: Kluwer Academic Publishers.

Husserl, E. 2001. Analyses Concerning Passive and Active Synthesis. Lectures on Transcendental Logic. Trans. A.J. Steinbock. Dordrecht: Kluwer Academic Publishers.

Kriegel, U. 2003a. Consciousness as sensory quality and as implicit self-awareness. Phenomenology and the Cognitive Sciences 2: 1-26.

Kriegel, U. 2003b. Consciousness as intransitive self-consciousness: two views and an argument. Canadian Journal of Philosophy 33: 103-132.

LeDoux, J. 2002. Synaptic Self. How Our Brains Become Who We Are. London: Penguin Books.

Legrand, D. 2003. How not to find the neural signature of self-consciousness. Consciousness and Cognition 12: 544-546. 
Legrand, D. 2005. The bodily self: the sensori-motor roots of pre-reflexive selfconsciousness. Phenomenology and the Cognitive Sciences, in press.

Maturana, H.R. 1969. The neurophysiology of cognition. In P. Garvin (ed.), Cognition: A Multiple View, pp. 3-23. New York: Spartan Books.

Maturana, H.R. 1970. Biology of cognition. In H.R. Maturana and F.J. Varela, Autopoiesis and Cognition: The Realization of the Living, pp. 2-58. Boston Studies in the Philosophy of Science. Volume 43. Dordrecht: D. Reidel.

Maturana, H. R. and Varela, F J. 1980. Autopoiesis and Cognition: The Realization of the Living. Boston Studies in the Philosophy of Science, vol. 42. Dordrecht: D. Reidel.

Maturana, H.R. and Varela, F.J. 1987. The Tree of Knowledge. The Biological Roots of Human Understanding. Boston: Shambala Press/New Science Library.

Merleau-Ponty, M. 1962. Phenomenology of Perception. Trans Colin Smith. London: Routledge Press.

Merleau-Ponty, M. 1964. Signs. Trans. Richard C. McCleary. Evanston, IL: Northwestern University Press.

Myin, E. and O'Regan, J.K. 2002. Perceptual consciousness, access to modality, and skill theories: a way to naturalize phenomenology? Journal of Consciousness Studies 9: 27-46.

Nagel, T. 1974. What is it like to be a bat? Philosophical Review 83:435-50.

Noë, A. 2002. Is perspectival self-consciousness non-conceptual? Philosophical Quarterly 52: 185-195.

Noë, A. 2004. Action in Perception. Cambridge, MA: The MIT Press.

Noë, A. and Thompson, E. 2004a. Are there neural correlates of consciousness? Journal of Consciousness Studies 11: 3-28.

Noë, A. and Thompson, E. 2004b. Sorting out the neural basis of consciousness. Authors' Reply to commentators. Journal of Consciousness Studies 11: 87-98.

O'Regan, J.K. and Noë, A. 2001a. A sensorimotor account of vision and visual consciousness. Behavioral and Brain Sciences 24: 939-1011.

O'Regan, J.K. and Noë, A. 2001b. Authors' response: acting out our sensory experience. Behavioral and Brain Sciences 24: 1011-1031.

O'Regan, J.K., Myin, E. and Noë, A. 2005. Sensory consciousness explained (better) in terms of 'corporality' and 'alerting capacity'. Phenomenology and the Cognitive Sciences, this volume.

Priest, S. 1998. Merleau-Ponty. London: Routledge Press.

Sheets-Johnstone, M. 1999. The Primacy of Movement. Amsterdam and Philadelphia, PA: John Benjamins Press.

Shoemaker, S. 1968. Self-reference and self-awareness. Journal of Philosophy 65: 55567.

Shoemaker, S. 1984. Identity, Cause and Mind. Philosophical Essays. Cambridge and New York: Cambridge University Press.

Thompson, E. 2001. Empathy and consciousness. In E. Thompson (ed.), Between Ourselves: Second-Person Issues in the Study of Consciousness, pp. 1-32. Thorverton, UK: Imprint Academic. Also published in Journal of Consciousness Studies 8 (2001): 1-32.

Thompson, E. 2004. Life and mind: from autopoiesis to neurophenomenology. A tribute to Francisco Varela. Phenomenology and the Cognitive Sciences 3: 381398.

Thompson, E. 2005. Empathy and human experience. In J.D. Proctor (ed.), Science, Religion, and the Human Experience. New York: Oxford University Press.

Thompson, E. and Varela, F.J. 2001. Radical embodiment: neural dynamics and consciousness. Trends in Cognitive Sciences 5: 418-425.

Thompson, E., Palacios, A., and Varela, F.J. 1992. Ways of coloring: comparative color vision as a case study for cognitive science. Behavioral and Brain Sciences 15: 1-74. Reprinted in Alva Noë and Evan Thompson (eds.), Vision and Mind: 
Readings in the Philosophy of Perception. Cambridge, MA: The MIT Press, 2002.

Varela, F.J. 1979. Principles of Biological Autonomy. New York: Elsevier North Holland.

Varela, F.J. 1991. Organism: a meshwork of selfless selves. In A. Tauber (ed.), Organism and the Origin of Self, pp. 79-107. Dordrecht: Kluwer Academic Publishers.

Varela, F.J. 1997. Patterns of life: intertwining identity and cognition. Brain and Cognition 34: 72-87.

Varela, F.J. and Bourgine, P. (eds.) 1991. Toward a Practice of Autonomous Systems. Proceedings of the First European Conference on Artificial Life (Cambridge, MA: The MIT Press.

Varela, F.J. and Thompson, E. 2003. Neural synchrony and the unity of mind: a neurophenomenological perspective. In A. Cleeremans (ed.), The Unity of Consciousness: Binding, Integration and Dissociation. New York: Oxford University Press.

Varela, F.J., Thompson, E. and Rosch, E. 1991. The Embodied Mind: Cognitive Science and Human Experience. Cambridge, MA: The MIT Press.

von Uexk!üll, J. 1957. A stroll through the worlds of animals and men. In K.S. Lashley (ed.), Instinctive Behavior: The Development of a Modern Concept, pp. 5-80. New York: International Universities Press.

Zahavi, D. 1999. Self-Awareness and Alterity. A Phenomenological Investigation. Evanston, IL: Northwestern University Press.

Zahavi, D. 2002. First-person thoughts and embodied self-awareness: some reflections on the relation between recent analytical philosophy and phenomenology. Phenomenology and the Cognitive Sciences 1: 7-26.

Zahavi, D. 2003. Husserl's Phenomenology. Stanford, CA: Stanford University Press.

Zahavi, D. 2004. Intentionality and phenomenality: a phenomenological take on the hard problem. In E. Thompson (ed.), The Problem of Consciousness: New Essays in Phenomenological Philosophy of Mind. Canadian Journal of Philosophy, Supplementary Volume. 